\title{
Construction of a Molecular Linkage Map of Pearl Millet Using SSR Markers
}

\author{
Anishetti Saritha ${ }^{1}$, Rakesh K Srivastava ${ }^{2}$, Narayan Reddy ${ }^{3}$, Pooja Katiyar ${ }^{2}$ and \\ Kuldeep Singh Dangi ${ }^{1^{*}}$ \\ ${ }^{1}$ Department of Genetics and Plant Breeding, College of Agriculture, Rajendranagar, 500030 \\ ${ }^{2}$ International Crops Research Institute for the Semi-Arid Tropics, Patancheru, 502324 \\ ${ }^{3}$ Department of Plant Pathology, College of Agriculture, Rajendranagar, 500030 \\ *Corresponding Author E-mail: dangiks24@gmail.com \\ Received: 15.07.2017 | Revised: 6.08.2017 | Accepted: 10.08.2017
}

\begin{abstract}
For pearl millet production in the semi-arid tropics, Sclerospora graminicola is a major biotic constraint causes Downy mildew. The pathogen is heterothallic and frequent recombination leads to evolution of new virulent populations. Identification of resistance to new virulent isolates is a prerequisite for resistance breeding. A very good understanding of ability to manipulate oligogenic and quantitative traits is offered to plant breeders by recent advances in genetic marker technology. In the present investigation, Genotypic data generated for a total of 39 marker loci (SSRs) were used to construct a linkage map of the pearl millet mapping population of 295 Recombinant Inbred Population based on the cross 81B-P13 × AIMP 92901-deriv-P03.A skeleton linkage map of seven linkage groups with a total map length of 536.8cMwasconstructed using Map Maker/Exp version $3.0 b$ at LOD threshold value of 3.0 and map was drawn using Map Chart 2.2. Among all the linkage groups of the present study, linkage groupl has the highest map length (146.6 cM) followed by linkage group 2 (98.3 cM). The linkage group $3(6.6 \mathrm{cM})$ has been recorded as the shortest among all seven linkage pearl millet groups in this study.
\end{abstract}

Key words: SSR Markers, Linkage group, Population, Genotypic

\section{INTRODUCTION}

Pearl millet is important as a staple food grain and source of feed and fodder for livestock, in hot, dry marginal agricultural production environments of Africa and South Asia. Downy mildew is the most destructive disease in India, caused by pathogen Sclerospora graminicola $[(\mathrm{Sacc})$. Schroet] in pearl millet. The important diseases that are responsible for economic losses in pearl millet are downy mildew, blast, smut, ergot and rust. Downy mildew is the most destructive disease in India, which is also referred to as green ear disease, where the grains are replaced by leaflike structures in the ear head. The estimated annual grain yield loss due to DM is approximately $20-40 \%{ }^{19}$, but this could be much higher under favourable conditions of disease development.

Cite this article: Saritha, A., Srivastava, R.K., Reddy, N., Katiyar. P. and Dangi, K.S., Construction of a Molecular Linkage Map of Pearl Millet Using SSR Markers, Int. J. Pure App. Biosci. 5(5): 1632-1640 (2017). doi: http://dx.doi.org/10.18782/2320-7051.5741 
Pearl millet is a good experimental plant for genetic studies because of its low diploid chromosome number $(2 \mathrm{n}=14)$ with a moderately high DNA content of IC $=2.36 \mathrm{pg}$. Its short duration (60-90 days), high genetic variability and its protogynous nature. It has also been recognized as a well suitable crop for molecular studies.

As the host is a crop of poor and marginal areas, the use of resistant cultivars is the most appropriate control method for pearl millet downy mildew in an integrated disease management system. Breeding for resistance to diseases contributes to increased productivity and stability of pearl millet grain, stover and forage yields. Hence, resistance breeding is a major component in pearl millet improvement programme.

A very good understanding of and ability to manipulate oligogenic and quantitative traits is offered to plant breeders by recent advances in genetic marker technology ${ }^{23}$. Molecular biology can be used to guide traditional plant breeding. Now hundreds of molecular markers have been created and detailed marker based genetic maps were produced for which the traits could be linked.

The first molecular marker-based genetic linkage map of pearl millet was built with restriction fragment length polymorphisms (RFLPs), the marker system of choice in the early 1990s. This map has served as the base for subsequent pearl millet markerbased studies at the John Innes Centre (J1C $)^{8}$,

Microsatellites remain the markers of choice for practical breeding applications with several advantages over RFLP, RAPD and AFLP markers. In addition, microsatellites exhibit co-dominant inheritance and their detection is readily automated. SSR markers are one of the best options available for foreground selection in marker-assisted backcrossing (MABC) programmes because they are hyper-variable, highly reproducible and readily multiplexed. They are also ideal for anchoring molecular linkage maps ${ }^{17}$.

The building up of a saturated molecular map using molecular markers like restriction fragment length polymorphisms (RFLPs) and microsatellites (SSR) makes it possible to dissect Mendelian factors underlying a complex trait such as disease resistance and consequently enhance the effectiveness and accelerate the rate of breeding programmes to improve pure line varieties of self-pollinated crops and hybrid parental lines of cross-pollinated crops. Linkage drag and confounding effects of environmental variation associated with conventional breeding can also be reduced ${ }^{10}$.

Therefore, in addition to breeding for yield contributing characters, more attention should be given for breeding resistant varieties and hybrids with higher yield. Disease resistance in high yielding varieties ensures farmers less dependence on chemical control and also avoid environmental pollution.

\section{MATERIAL AND METHODS Genomic DNA Isolation:}

The seedlings of parents and mapping population were grown in a growth room in 30 $\mathrm{mm}$ diameter hydrated Jiffy-7 pellets were placed in plastic trays and watered for every 2 days. $100 \mathrm{mg}$ of leaf tissue were collected from seedlings of 6 days after sowing and placed in $12 \times 8$-well strip tubes with strip caps in a 96 deep-well plate together with three 4-mm stainless steel grinding balls, then added 500 $\mu 1$ of preheated $\left(65^{\circ} \mathrm{C}\right)$ SDS extraction buffer and $3 \mu$ proteinase- $K$ to each sample and secured with 8-strip caps and processed samples in a Geno Grinder. Incubated the samples for $30 \mathrm{~min}$ in a $65^{\circ} \mathrm{C}$ water bath with occasional mixing and taken out the samples from water bath and kept for 5 minutes at room temperature to avoid bumping and centrifused. Added $400 \mu \mathrm{l}$ of phenol chloroform-isoamylalcohol $(25: 24: 1)$ to each sample and inverted twice to mix the samples then centrifuged plates at $6000 \mathrm{rpm}$ for 15 min. Transferred aqueous layer (supernatant) to fresh strip tubes. Added $400 \mu \mathrm{l}$ of chilled isopropanol (stored at $-20^{\circ} \mathrm{C}$ ) to each sample and inverted to mix the samples. Centrifuged plates at $6000 \mathrm{rpm}$ for $15 \mathrm{~min}$., decant supernatant from each sample and air-dried 
pellet for $30 \mathrm{~min}$. Added $200 \mu \mathrm{l}$ low-salt $\mathrm{T}{ }_{10} \mathrm{E}$ ${ }_{1}$ buffer to each sample and $3 \mu \mathrm{R}$ Nase A (10 $\mathrm{mg} / \mathrm{ml}$ ) to each sample and incubated at $37^{\circ} \mathrm{C}$ for 60 min with gentle shaking in between and centrifused for 15 seconds at $5800 \mathrm{rpm}$. Added $210 \mu \mathrm{l}$ phenol-chloroform-isoamylalcohol (PCI, 25:24:1) to each sample and invert twice to mix the samples. Centrifuged plates at 5800 rpm for $10 \mathrm{~min}$. Transfered fixed volume of aqueous layer to a fresh 96 deep-well plate and added $210 \mu \mathrm{l}$ chloroform-isoamylalcohol (24:1) to each sample and inverted twice to mix and Centrifuged plates at5800 rpm for 10 min. Transferred fixed volume of aqueous layer to a fresh 96 deep-well plate.

Added $350 \mu 1$ ethanol - sodium acetate (3M, pH 5.2) solution to each sample and placed in $-20^{\circ} \mathrm{C}$ for 30 min.Centrifuged plate at $6000 \mathrm{rpm}$ for $12 \mathrm{~min}$., removed supernatant from each sample and washed pellets with $70 \%$ ethanol and centrifuged plates at 6200 rpm for $10 \mathrm{~min}$. Removed supernatant from each sample and air dried upto the no smell of ethanol to the samples. Resuspended pellet in $100 \mu$ low-salt $T_{10} E_{1}$ buffer for DNA dilution and stored at $4{ }^{\circ} \mathrm{C}$.

The quality of genomic DNA was examined by using agarose $(0.8 \%)$ gel electrophoresis and quantity was accurately quantified by using Nanodrop (Nanodrop 8000 Spectrophotometer).

To prepare $0.8 \%$ gel, $0.8 \mathrm{~g}$ of agarose was melted in $100 \mathrm{ml}$ of $1 \mathrm{X}$ TBE buffer in microwave oven and cooled to $50^{\circ} \mathrm{C}$ by keeping in running tap water. Now, $5 \mu 1$ of 10 $\mathrm{mg} / \mathrm{ml}$ stock of Ethidium Bromide was added to it. The gel plate was sealed on both sides with tape and a combs were inserted and the gel solution was poured in it gently. It was allowed to solidify for 30 minutes. After setting, the seal tapes were removed from both sides and combs were removed gently. The gel plate was placed in an electrophoresis unit and it was filled with 0.5X TBE buffer.

The DNA sample was prepared by adding $2 \mu l$ of gel loading dye and $1 \mu l$ of the DNA sample and then it was loaded on agarose gel and electrophoresis unit was run at $80 \mathrm{~V}$ for 20 minutes and then gel was visualized under UV and photographed on the gel documentation system. After quantification of DNA, it was diluted to $5 \mathrm{ng} / \mu \mathrm{l}$.

For preparing working solutions of uniform DNA concentration from the above samples, the following formulae was used:

DNA concentration $(5 \mathrm{ng} / \mu \mathrm{l})$ for total dilution of volume of $1000 \mu \mathrm{l}$ for PCR reactions:

$$
=\left(\begin{array}{lllll}
5 & \mathrm{ng} / \mu \mathrm{l} & \mathrm{x} & 1000 & \mu \mathrm{l}
\end{array}\right) \div \text { DNA }
$$

concentration of stock solution.

DNA degradation and contamination with other substances were checked by electrophoresis of aliquot of samples in agarose gels $(0.8 \%)$. It was assumed that large molecular weight DNA appears as a band with sharp edges, whereas partially degraded material forms a smear of long to small fragments. The amount of DNA was also approximated utilizing UV-induced fluorescence emitted by Ethidium Bromide molecules intercalated into the DNA, because the amount of fluorescence is proportional to the total mass of DNA. The quantity of DNA sample was estimated by comparing the fluorescent yield of the sample with that of a series of uncut lambda DNA standards.

According to Anolles ${ }^{4}$. the parameters of DNA amplification (viz., specificity, efficiency and fidelity) are strongly influenced by the different components of the reaction and by thermal cycling. Therefore, the careful optimization of these parameters will ultimately result in reproducible and efficient amplification.

PCR conditions for pearl millet SSR primers were optimized using a grid with various amounts and concentrations of chemicals used for the PCR master mix, at different annealing temperatures. Among the SSR markers used, the PSMP series genomic SSR markers were obtained from Qi et al. ${ }^{15,14}$, and Allouis et al. ${ }^{3}$, The ICMP series EST-SSR markers were published by Senthilvel et al. ${ }^{18}$, The IPES series EST-SSR markers were obtained from Rajaram et al. ${ }^{17}$, and STS markers developed at John Innes Centre, UK. To identify SSR primer pairs detecting polymorphism between parents, initial screening of parentallines was conducted using 
ABI 3730 DNA analyzer. For this, DNA was extracted from 81B -P13 (taken as first parent i.e. $\mathrm{P}_{1}$ ) and AIMP 92901-P03 (taken as second parent i.e. $\mathrm{P}_{2}$ ). A total of 500 primers were used to screen the parents. From this screening, 125 SSR primers detecting scorable polymorphism between the parents were noted and used for further screening of the RIL mapping population of these parents.

The PCR reactions were conducted in a Peltier Thermo cycler Biorad DNA Engine Dyad and Gene Amp ${ }^{\circledR}$ PCR system 9700 . The standard PCR reagents in a total reaction volume of $5 \mu$ were: Genomic DNA template

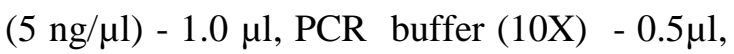
$\mathrm{M} \mathrm{g}^{2+}(25 \mathrm{mM})-0.12 \mu \mathrm{l}$, DNTP mix $(2 \mathrm{mM})$ $0.3 \mu 1$, Primer - $0.5 \mu 1$, Taq DNA polymerase $(5 \mathrm{U} / \mu \mathrm{l})$ - $0.05 \mu \mathrm{l}$, De-ionized distilled water $2.53 \mu 1$.

The cycling conditions for SSR primers were set up using touchdown PCR thermo cycling with minor modifications and Gradient PCR. The details of the standard touchdown PCR programme are as follows:

$94^{\circ} \mathrm{C}$ - 5 minutes hold (initial denaturation), $94^{\circ} \mathrm{C}-15$ seconds (denaturation), $* 61^{\circ} \mathrm{C}-20$ seconds (primer annealing), $*=1^{\circ} \mathrm{C}$ drop per cycle for 10 cycles, $72^{\circ} \mathrm{C}-30$ seconds (primer extension), $94^{\circ} \mathrm{C}-10$ seconds (denaturation), $56^{\circ} \mathrm{C}-20$ seconds (primer annealing) for 35 cycles, $72^{\circ} \mathrm{C}-30$ seconds (primer extension), $72^{\circ} \mathrm{C}$ - 20 minutes hold, $04^{\circ} \mathrm{C}$ - storage

However, changes in annealing temperatures (from $56^{\circ} \mathrm{C}$ to $62^{\circ} \mathrm{C}$ ) were followed for some primers as per the temperature range required for the respective primers to achieve optimization of the amplified products.

For separation and visualization of PCR products, agarose (1.2\%), polyacrylamide gels $(6 \%)$ and ABI analyser were used. Agarose gels were used mainly for initial visualization/checking of amplification because exact sizing of microsatellite alleles cannot be accomplished on agarose and it is difficult to distinguish two, three or four basepair differences in DNA fragment length ${ }^{7}$, Therefore, scoring of allele size differences of PCR amplified products of most of the primers was performed in polyacrylamide gels and
$\mathrm{ABI}$ and some are on agarose itself for those primers having band size difference of more than 10 base pairs.

\section{Agarose Gel Electrophoresis}

Agarose $1.2 \%$ gels were cast in TBE buffer $(0.5 \mathrm{X})$. Gels were cast in a horizontal gel frame (Thermo Scientific OWL D3-14) and products were visualized by incorporating $1 \mu 1$ $(10 \mathrm{mg} / \mathrm{ml})$ Ethidium Bromide (EB) per $20 \mathrm{ml}$ of gel solution and viewed in a gel documentation system. Here the main purpose of running agarose gels (for 15-30 minutes at $100 \mathrm{~V})$ was to check whether amplification of PCR product has taken place or not before attempting to separate this PCR product on PAGE and ABI 3730 DNA analyzer as later two takes more time than the agarose checking.

\section{Polyacrylamide Gel Electrophoresis (PAGE)}

For separation and visualization of PCR products, $6 \%$ polyacrylamide gels were used.

The details of gel preparation, electrophoresis and visualization of separated DNA bands are given below.

\section{Gel Preparation and Electrophoresis}

Polyacrylmide gels allow high resolution of amplified products ( $>5$ base-pair differences in DNA fragment length) from PCR. For separating amplified products of SSR primers, non-denaturing polyacrylmide gels $(6 \%)$ were used. Before preparation of gel solution, glass plates were cleaned thoroughly with ethanol. A few drops of repel-silane-ES were applied to the back plate and rubbed over the surface. This makes it easier to separate the plate from the gel. To the front glass plate a few drops of bind silane were applied and rubbed over its entire surface. This prevents the gel from dislodging during staining.

1) For a $6 \%$ gel (Bio-Rad plates) $75 \mathrm{ml}$ of gel solution was prepared by mixing $8.0 \mathrm{ml}$ TBE buffer (10X), $\quad 15.0 \mathrm{ml}$ of 29:1 (w/w) acrylamide: bis-acrylamide solution, $52.0 \mathrm{ml}$ distilled water.

2) The contents of the gel solution were mixed vigorously. TEMED $(90 \mu \mathrm{l})$ was added and mixed by swirling the flask. 
3) Immediately added $400 \mu \mathrm{l}$ of $10 \%$ (w/v) APS (ammonium per-sulphate) and mixed by swirling the flask.

4) Acrylamide solution was poured into the syringe, which feeds it between the glass plates, and the comb was inserted to produce track-loading wells at the top of the gel.

5) After polymerization the gel was set up for running electrophoresis. The comb was removed. The lower tank was filled with TBE $(0.5 \mathrm{X}$, approximately $300 \mathrm{ml})$ and the back of the plate and upper reservoir with the same (approximately $400 \mathrm{ml}$ ), ensuring that the well was covered. Each well was aspirated with TBE buffer using a Pasteur pipette to remove small fragments of gel and tiny bubbles. The gel was pre run for at least $20 \mathrm{~min} 900 \mathrm{~V}$ to warm it.

6) The samples were made up for loading in loading buffer, $2 \mu 1$ were loaded into each well on the gel. Lambda size markers $(2 \mu 1$ of 50 $\mathrm{ng} / \mu \mathrm{l})$ were loaded along with the samples.

7)The gel was run at approximately $600 \mathrm{~V}$ for 3 hrs. until the desired resolution was reached. This was determined by the dye front.

8) After the run, the plates were carefully pulled apart so that the gel remained attached to the front glass plate.

\section{Silver Staining and Visualization of Bands}

Electrophoresed DNA fragments were detected with silver nitrate staining ${ }^{9}$,

DNA polymorphism among the parents was observed based on length of amplified fragments in terms of number of base pairsby comparing with a 100 base pair ladder $(50 \mathrm{ng} / \mu \mathrm{l})$. The scoring of RIL population was given by comparing the bands of parents. The images showing parental polymorphism for some SSR primer pairs on a polyacrylamide gel visualized by silver staining.

\section{Analysis of PCR Product on ABI 3730 DNA} Analyzer

Polymerase chain reaction products were pooled after PCR, which contained $1 \mu$ of each of dye labeled (FAM, VIC, NED and PET) product, $7 \mu \mathrm{l}$ of formamide, $0.3 \mu \mathrm{l}$ of the LIZ-labeled (500 [-250]) size standard and 4.2 $\mu l$ of distilled water. The DNA fragments were size separated by capillary electrophoresis on an ABI 3730 automatic DNA sequencer (Applied Biosystems). Gene Mapper v4.0 (Applied Biosystems, USA) was used to size the peak patterns by using the internal LIZlabeled (500 [-250]) size standard. The pooling of PCR products should be having more than 30 base pairs difference to avoid the confusion of peak selection at scoring through Gene Mapper analysis ${ }^{13}$.

After scoring, the individual progeny genotypes were typed in a Microsoft Excel spread sheet in a format suitable for linkage analysis by MapMaker/Exp. (i.e., rows = genotype score at a given locus; columns = RIL mapping population individuals).

$$
\text { MapMaker/Exp version } 3.0 \mathrm{~b}
$$

multipoint analysis ${ }^{11}$, was used to construct the linkage map using a LOD threshold value of 3.0. After formation of seven linkage groups, markers were placed based on "group", "sequence" and "map" commands. Unlinked markers were then placed in appropriate linkage groups using the "build" and "try" command. Markers with satisfactory orders were then anchored in each linkage group. The distances were calculated in centi Morgan using Haldane mapping function and the map was drawn using Map Chart 2.22 .

\section{RESULTS AND DISCUSSION}

Genotypic data generated for a total of 39 marker loci (SSRs) were used to construct a linkage map of the pearl millet mapping population of 295 Recombinant Inbred Population based on the cross 81B-P13 $\times$ AIMP 92901-deriv-P03. A previously constructed integrated consensus pearl millet linkage map ${ }^{17}$, based on SSR markers was used as a reference for marker linkage group assignment and initial marker ordering in this study.

A linkage map of seven linkage groups (LGs) with a total map length of $536.8 \mathrm{cM}$ was constructed using data from 39 marker loci for 295 RILs. The map lengths of individual linkage groups ranged from a minimum of $6.6 \mathrm{cM}$ (LG3) to a maximum of $146.6 \mathrm{cM}$ (LG1). (figure1). 


\section{Linkage Group 1}

Linkage group 1 accommodated five loci detected by Xipes0017, Xipes0146, Xicmp3017, Xipes0045 and Xipes0127. This was the largest linkage group for this mapping population with a Haldane map length of 146.6cM. Marker locus Xipes127 was placed at the bottom of this linkage group at map distance of $94.2 \mathrm{cM}$ from Xipes0045.

\section{Linkage Group 2}

This linkage group consisted of highest number of ten markers (table-1) with a total map length of $98.3 \mathrm{cM}$. The order of markers were Xipes0163, Xipes0117, Xipes0003, Xpsmp2206, Xpsmp2232, Xpsmp2077, Xpsmp2059, Xipes0236, Xipes0118 and Xipes0221. This is the second highest largest linkage group after LG1.

\section{Linkage Group 3}

This was the shortest linkage group among the seven in this skeleton map. It has a total map length of $6.6 \mathrm{cM}$ and consist of three markers. These markers were placed in the order of Xipes0233, Xpsmp2070 and Xipes0166 withinter-marker distances of 3.3.

\section{Linkage Group 4}

Seven markers were placed in this linkage group with an order of Xipes187, Xipes0174, Xpsmp 2076, Xipes0129, Xipes0076, Xipes66 and Xipes0114. This linkage group has a total map length of $75.8 \mathrm{cM}$.

\section{Linkage Group 5}

The total map length of linkage group 5 is $71.2 \mathrm{cM}$. The markers are arranged in the order of Xipes0191, Xpsmp2274 and Xipes0214. Xipes0214 placed at a more distance of $51.2 \mathrm{cM}$ from nearest marker Xpsmp2274.

\section{Linkage Group 6}

This linkage group consisted of six markers with the order of Xipes0200, Xipes0176, Xipes0071, Xipes0035, Xicmp3050 and Xipes0189 having the total map length of 52.9cM. The marker Xipes0189 placed at a distal region at a larger distance of $40.6 \mathrm{cM}$ from Xicmp3050. The remaining loci in this linkage group were located close toeach other with inter-marker intervals (ranging from $0.4 \mathrm{cM}$ to $6.5 \mathrm{cM}$ )

\section{Linkage Group 7}

The order of markers in this linkage group was Xipes0105, Xipes0026, Xpsmp2224, Xipes97 and Xpsmp2210 with the total map length of $85.4 \mathrm{cM}$.

Based on $\mathrm{F}_{2}$ mappingpopulation from cross LGD 1-B-10 × ICMP 85410, Liu et al. (1994) using RFLP markers constructed linkage map with a genome length of $287.7 \mathrm{cM}$. Allen ${ }^{2}$, constructed a smaller linkage map of $421 \mathrm{cM}$ (Haldane units) from a population of $175 \mathrm{~F}_{2}$ individuals using38 RFLP markers. Azhaguvel (2003) constructed a linkage map of 562cM (Haldane units) using 33 well-distributed RFLP markers, having comparatively larger mapped genome length for his mapping population than the present mapping population study. The linkage map constructed in the present study based on $\mathrm{F}_{7}$ RILs from the cross of $81 \mathrm{~B}-\mathrm{P} 13 \times$ AIMP 92901-deriv-P03 has a total map length of $536.8 \mathrm{cM}$. Compared to the previous linkage maps of pearl millet, present map length has fall in the intermediate position.

Among all the linkage groups of the present study, LG1 has the highest map length followed by LG2. The order of markers located on all linkage groups were mostly same as mentioned in pearl millet consensus map based on four mapping populations ${ }^{17}$. The total number of mapped loci per linkage group ranged from 3 on LG3 to 10 on LG2. The linkage group 3 has been recorded as the shortest among all seven linkage pearl milletgroups in this study, which is in complete agreement with previous studies in crosses841B x 863B (Yadavet al., 2004), 81BP6 x ICMP 451-P6 ${ }^{8,14}$, W 504-1-1 xP310-17$\mathrm{B}^{2}$, and PT $7328 \times \mathrm{P} 14492^{12}$,

The shortage of markers to be mapped in both the upper and lower distalregions away from the centromere of the linkage group 1 and 5 created the gaps in these linkage groups. This is in line with earlier reports where large inter-marker distances were reported towards the distal ends of linkage groups ${ }^{14,18}$, In case of linkage group 6, all the markers were located close to each other with shorter inter marker distances, created shorter map length of this group. 
Increase in map length of the present study was not observed, because less number of markers were used for linkage analysis and all the polymorphic markers used were occupied at a shorter inter marker distances in some groups, while in others, markers were localised at the positions of central regions, leaving the distal regions created the gaps in the linkage map.

The relatively large population size (295 RILs from 81B-P13×AIMP92901 derivP03) used for construction of the genetic linkage mapspresented here as compared with other studies ${ }^{16,1,21}$, was highly advantageous for further exploitation of these maps. These larger population sizes improvethe estimation of marker orders, which in turn improves the resolution of QTL mapping ofagronomic traits. They also enable a greater resolution in the positioning of QTLs on the geneticmap, while distribution of markers across the full length of the genome is required to detect allcontributing loci ${ }^{6}$,

Once linkage between a marker locus and the gene for an agronomic trait of interest has been established, DNA diagnostic tests can be used to guide plant breeding as a substitute for other phenotypic tests such as assays for disease resistance. The development and availability of abundant, naturally occurring molecular genetic markers (RFLP, RAPD and isozymes etc.,) during last two decades has generated renewed interest in counting, locating and measuring the effects of genes (polygenes or QTLs) controlling quantitative traits ${ }^{5}$, This linkage map can be used for the identification of Quantitative TraitLoci, for the resistance breeding programme in the Pearl Millet breeding study.

Table 1: The number of markers on each linkage group

\begin{tabular}{|c|c|}
\hline LINKAGE GROUP (LG) & NUMBER OF MARKERS \\
\hline LG1 & 5 \\
\hline LG2 & 10 \\
\hline LG3 & 3 \\
\hline LG4 & 7 \\
\hline LG5 & 3 \\
\hline LG6 & 6 \\
\hline LG7 & 5 \\
\hline
\end{tabular}
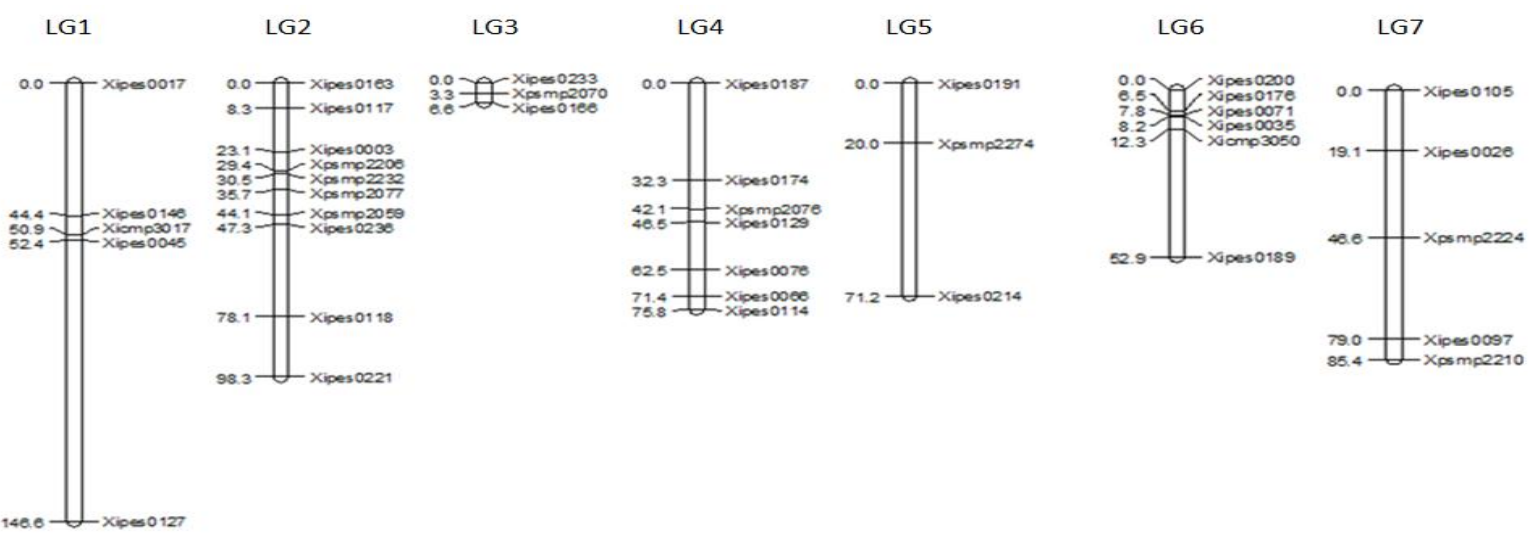

Fig. 1: Genetc linkage map of pearl milllet linkage groups (1-7) based on cross 81 B-P13 and AIMP 92901-deriv-P03. Left side of the map of each linkage group are marker distsnces in cM (Haldane units) and on right side are the name of markers

LG1- Linkage group1 ; LG2-Linkage group2; LG3 - Linkage group3; LG4 - Linkage group4; LG5 - Linkage group5; LG6 Linkage group6; LG7 - Linkage group7 


\section{Acknowledgments}

I thank Acharya N.G. Ranga Agricultural University (ANGRAU) for financial help in the form of stipend during the course of work.

\section{REFERENCES}

1. Akbari, M., Wenzl, P., Caig, V., Carling, J., Xia, L., Yang, S., Uszynski, G., Mohler, A., Lehmensiek, A., Kuchel, H., Hayden, M.J., Howes, N., Sharp, P., Vaughan, P., Rathnell, B., Huttner, E and Kilian, A., Diversity arrays technology (DArT) for high throughput profiling of the hexaploid wheat genome. Theoritical and Applied Genetics. 113: 1409-1420. (2006).

2. Allen, K.M., Mapping new quantitative trait loci (QTL) for downy mildew resistance in pearl millet. Ph. D Thesis. Russian Academy of Sciences, Moscow. (2001).

3. Allouis, S., Qi, X., Lindup, S., Gale, M.D and Devos, K.M., Construction of a BAC library of pearl millet, $C$. Theoritical and Applied Genetics. 102: 1200-1205. (2001).

4. Anolles, G.C., Nucleic scanning by amplification with mini-hairpin and microsatellite oligonucleotide primers.In G.C. Anolles and P.M. Gresshoff (eds.) DNA markers: protocols, applications and overviews. Wiley-Liss, Inc., New York. 91-114. (1997).

5. Azhaguvel, P., Linkage map construction and identification of QTLs for downy mildew (Sclerospora graminicola) resistance in pearl millet [Pennisetum glaucum (L.) R. (2001).

6. Chalmers, K.J., Campbell, A.W., Kretschmer, J., Karakousis, A., Henschke, P.H., Pierens, S., Harker, N.,Pallotta, M., Cornish, G.B., ShariXou, M.R., Rampling, L.R., McLauchlan, A., Daggard, G., Sharp,P.J., Holton, T.A., Sutherland, M.W., Appels, $\mathrm{R}$ and Langridge, P., Construction of threelinkage maps in bread wheat, Triticum aestivum. Australian Journal of Agricultural Reserch. 52: 1089-1119 (2001).
7. Cregan, $P$ and Quigley, C.V. Simple sequence repeats DNA marker analysis. In G.C. Anolles and P.M. Gresshoff (eds.) DNA markers: protocols, applications and overviews. Wiley-Liss, Inc., New York. 173-185. (1998).

8. Devos, K.M., Pittaway, T.S., Reynolds, A and Gale, M.D., Comparative mappingreveals a complex relationship between the pearl millet genome and those offoxtail millet and rice. Theoritical and Applied Genetics. 100: 190-198. (2000).

9. Goldman, D and Merril, C.R., Silver staining of DNA in polyacrylamide gels: linearity and effect of fragment size. Electrophoresis.3: 24-26.( 1982).

10. Gulia, S.K., QTL mapping for improvement of downy mildew [Sclerospora graminicola (sacc.) J. schroet.] resistance (DMR) in pearl millet (Pennisetum glaucum (L.) R. Br.) hybrid parental line ICMB 89111. Ph. D Thesis. Chaudhary Charan Singh Haryana Agricultural University, Hisar, India. (2004).

11. Lincoln, S., Daly, $M$ and Lander, E., Constructing genetic maps with MAPMAKER/EXP 3.0. Whitehead Institute Technical Report. $3^{\text {rd }}$ ed. (1992b).

12. Nepolean, T., Identitication of QTLs for yield and its component traits and downy mildew [Sclerospora graminicola (Sacc.) $J$. Schrot.]resistance in pearl millet [Pennisetumglaucum(L.) R. Br.]. Ph.D Thesis. Tamil Nadu Agricultural University, Coimbatore, India. (2002).

13. Nepolean, T., Gupta, S.K.,Dwivedi, S.L.,Bhattacharjee, R., Rai, K. N. and Hash, C.T. , Genetic Diversity in Maintainer and Restorer Lines of Pearl Millet. Crop Science. 52: 2555-2563. (2012).

14. Qi, X., Pittaway, T.S., Lindup, S., Liu, H., Waterman, E., Padi, F.K., Hash, C.T., Zhu, J., Gale, M.D and Devos, K.M., An integrated genetic map and a new set of simple sequence repeat markers for pearl millet, Pennisetum glaucum. Theoritical 
and Applied Genetics.109: 1485-1493. (2004).

15. Qi, X., Lindup, S., Pittaway, T.S., Allouis, S., Gale, M.D and Devos, K.M., Development of simple sequence repeats markers from bacterial artificialchromosomes without subcloning. Bio Techniques.31: 355-361. (2001).

16. Quarrie, S.A., Steed, A., Calestani, C., Semikhodskii, A., Lebreton, C., Chinoy, C., Steele, N., Pljevljakusi, D., Waterman, E., Weyen, J., Schondelmaier, J., Habash, D.Z., Farmer, P., Saker, L., Clarkson,D.T., Abugalieva, A., Yessimbekova, M., Turuspekov, Y., Abugalieva, S., Tuberosa, R., Sanguineti,M.C., Hollington, P.A., Aragués, R., Royo, A and Dodig, D. A high-density genetic map ofhexaploid wheat (TriticumaestivumL.) from the cross Chinese Spring $x$ SQ1 and its use to compareQTLs for grain yield across a range of environments. Theoritical and Applied Genetics. 110:865-880. (2005).

17. Rajaram, V., Nepolean, T., Senthilvel, S., Varshney, R.K., Vadez, V., Srivastava, R.K., Shah, T.M., Supriya, A., Kumar, S., Kumari, B.R., Bhanuprakash, A., Narasu, M.L., Lizarazu, O.R and Hash, C.T., Pearl millet consensus linkage map constructed using four RIL mapping populations and newly developed EST-SSRs. BMC Genomics.14:159. (2013).
18. Senthilvel, S., Jayashree, B., Mahalakshmi, V., Kumar, P.S., Nakka, S., Nepolean, T and Hash, C.T., Development and mapping of Simple Sequence Repeat markers for pearl millet from data mining of Expressed Sequence Tags. BMC Plant Biology.8: 119. (2008).

19. Thakur, R.P., Rai, K.N., Khairwal, I.S., Mahala, R.S., Strategy for downy mildew resistance breeding in pearl millet in India. SAT ejournal. 6: 1-11.(2008).

20. Thakur, R.P., Shetty, K.G and King, S.B. Selection for host-specific virulence in asexual population of Sclerospora graminicola. Plant Pathology.41: 626632.(1992).

21. Vengadessan, V., Rai, K.N., Bapu, J.R.K., Hash, C.T., Bhattacharjee, R., Senthilvel, S.,Vinayan, M.T and Nepolean, T., Construction of genetic linkage map and QTL analysis of sink-size traits in pearl millet (Pennisetum glaucum).International Scholarly Research Notices.1-14. (2013).

22. Voorrips, R.E., Map Chart: software for the graphical presentation of linkage maps and QTLs. Journal of Heredity. 93: 77-7. (2002).

23. Young, N.D. A cautiously optimistic vision for marker-assisted breeding. Molecular Breeding. 5: 505-510. (1999). 